\title{
The Neural Cell Adhesion Molecule L1 Interacts with the AP-2 Adaptor and Is Endocytosed via the Clathrin-Mediated Pathway
}

\author{
Hiroyuki Kamiguchi, ${ }^{1}$ Kristin E. Long, ${ }^{1}$ Maryanne Pendergast, ${ }^{1}$ Andrew W. Schaefer, ${ }^{1}$ Iris Rapoport, ${ }^{2}$ \\ Tomas Kirchhausen, ${ }^{2}$ and Vance Lemmon ${ }^{1}$ \\ ${ }^{1}$ Department of Neurosciences, Case Western Reserve University, Cleveland, Ohio 44106, and 2Department of Cell \\ Biology and the Center for Blood Research, Harvard Medical School, Boston, Massachusetts 02115
}

\begin{abstract}
Cell-cell interactions mediated via cell adhesion molecules (CAMs) are dynamically regulated during nervous system development. One mechanism to control the amount of cell surface CAMs is to regulate their recycling from the plasma membrane. The L1 subfamily of CAMs has a highly conserved cytoplasmic domain that contains a tyrosine, followed by the alternatively spliced RSLE (Arg-Ser-Leu-Glu) sequence. The resulting sequence of $\underline{Y R S} \underline{\mathrm{L}}$ conforms to a tyrosine-based sorting signal that mediates clathrin-dependent endocytosis of signal-bearing proteins. The present study shows that L1 associates in rat brain with AP-2, a clathrin adaptor that captures plasma membrane proteins with tyrosine-based signals for endocytosis by coated pits. In vitro assays demonstrate that this interaction occurs via the YRSL sequence of $L 1$ and the $\mu 2$ chain of AP-2. In L1-transfected 3T3 cells, L1 endocytosis is
\end{abstract}

blocked by dominant-negative dynamin that specifically disrupts clathrin-mediated internalization. Furthermore, endocytosed L1 colocalizes with the transferrin receptor (TfR), a marker for clathrin-mediated internalization. Mutant forms of $L 1$ that lack the YRSL do not colocalize with TfR, indicating that the YRSL mediates endocytosis of L1. In neurons, L1 is endocytosed preferentially at the rear of axonal growth cones, colocalizing with Eps15, another marker for the clathrin endocytic pathway. These results establish a mechanism by which L1 can be internalized from the cell surface and suggest that an active region of $\mathrm{L} 1$ endocytosis at the rear of growth cones is important in L1-dependent axon growth.

Key words: neural cell adhesion molecule; L1; tyrosine-based sorting signal; clathrin-mediated endocytosis; AP-2 adaptor; axonal growth cone
Cell adhesion molecules (CAMs) in the immunoglobulin (Ig) superfamily play critical roles in neuronal migration and axon growth and guidance (Brümmendorf and Rathjen, 1994). An important subfamily of Ig CAMs includes L1, neurofascin, and NrCAM, which are expressed at relatively high levels on axons and growth cones. The fact that humans and mice with L1 mutations have defects in major axonal tracts confirms the importance of this class of molecules (Cohen et al., 1997; Dahme et al., 1997; Fransen et al., 1998; Kamiguchi et al., 1998).

For a cell to respond rapidly to changes in environmental situations, the cell must be able to regulate the function and/or expression of its CAMs. Little is known about how the function of L1 subfamily members is regulated on a time scale of minutes, especially in neuronal growth cones, where regulation via transcription or translation is not possible locally. One way to control the amount of L1 on the cell surface is to regulate its recycling from and to the plasma membrane. Because it has been shown that integrins are endocytosed at the rear of migrating cells and

\footnotetext{
Received Jan. 6, 1998; revised April 14, 1998; accepted April 27, 1998.

This work was supported by National Institutes of Health (NIH) Grants EY-5285 and NS-34252, Vision Center Grant (P30 EY11373), and Program Project Grant (PO1 NS32779) to V.L. and by NIH Grant GM 36548 to T.K. We acknowledge the excellent technical assistance of Guanghui Cheng and Zhenhua Miao. We are grateful to Dr. Sandra Lemmon and members of her laboratory, especially Dr. Kristen Huang, who helped to introduce us to the use of yeast two-hybrid technology. We also thank Drs. Juan Bonifacino, Stephen Elledge, and Sandra Schmid for providing DNA constructs and Drs. Cathleen Carlin, Susann Brady-Kalnay, and Sandra Lemmon for helpful comments on this manuscript.

Correspondence should be addressed to Dr. Vance Lemmon, Department of Neurosciences, Case Western Reserve University, 2109 Adelbert Road, Cleveland, OH 44106-4975.

Copyright (C) 1998 Society for Neuroscience $\quad 0270-6474 / 98 / 185311-11 \$ 05.00 / 0$
}

recycled to the front (Lawson and Maxfield, 1995; Palecek et al., 1996), it is plausible that a similar phenomenon occurs in growth cones advancing via an L1-dependent mechanism.

Clathrin-coated pits and vesicles provide for the rapid endocytosis of plasma membrane proteins (Mellman, 1996). The cytoplasmic domains of some membrane proteins contain tyrosinebased sorting signals that direct clathrin-mediated endocytosis. Tyrosine-based signals conform to the motif $\mathrm{Yxx} \emptyset$, where $\mathrm{x}$ is any amino acid and $\varnothing$ is an amino acid with a bulky hydrophobic side chain (Trowbridge et al., 1993). The assembly of clathrin coats at the plasma membrane depends on the adaptor complex AP-2 (Gallusser and Kirchhausen, 1993), which is composed of two large chains ( $\alpha$-adaptin and $\beta 1$ - or $\beta 2$-adaptin), one medium chain $(\mu 2)$, and one small chain $(\sigma 2)$. The $\mu 2$ chain of AP-2 interacts with the tyrosine-based signal (Ohno et al., 1995; Rapoport et al., 1997) and concentrates the signal-bearing molecules in clathrin-coated areas of the plasma membrane (Kirchhausen et al., 1997; Marks et al., 1997).

L1 subfamily members have a highly conserved cytoplasmic domain (Hortsch, 1996). Near the middle of the cytoplasmic domains is an alternatively spliced RSLE (Arg-Ser-Leu-Glu) sequence (Miura et al., 1991). In L1, the RSLE sequence is expressed in neurons, but not in other L1-expressing cells such as Schwann cells (Takeda et al., 1996). The RSLE sequence is preceded by a tyrosine in L1 subfamily members. The resulting YRSL sequence conforms to the tyrosine-based sorting signal YxxØ. We have found that the YRSL sequence mediates L1 endocytosis by interacting with AP-2. We also have found that clathrin-dependent endocytosis of L1 preferentially occurs at the rear of axonal growth cones. In this way the surface expression of 
L1 can be regulated dynamically and spatially, which is likely to be crucial for growth cone motility.

\section{MATERIALS AND METHODS}

Yeast two-hybrid system. The genotype of HF7c yeast (Clontech Laboratories, Palo Alto, CA) is MATa ura3-52 his3-200 lys2-801 ade2-101 trp1-901 leu2-3,112 gal4-542 gal80-538 LYS2::GAL1-HIS3 URA3::(GAL4 17-mers) ${ }_{3}$-CYC1-lacZ. Yeast were grown on YEPD (yeast extract, peptone, dextrose) or on yeast minimal synthetic dextrose dropout media (C-nutrient), prepared as described previously (Nelson and Lemmon, 1993).

The cDNAs encoding the whole cytoplasmic domains of human L1FL, L1Y1176A, or L1 $\triangle$ RSLE (see Fig. 1) were made with PCR amplification of the L1FL, L1Y1176A, or L1 $\triangle$ RSLE cDNA in pBluescript II KS ${ }^{+}$(Wong et al., 1995; Kamiguchi and Lemmon, 1998), respectively. The primers used were 5'-CGCCATGCCATGGTCAAGCGCAGCAAGGGC-3' and 5'GCGGATCCACTATTCTAGGGCCAC-3'. The PCR products were subcloned into PCR2.1 vecto, using a TA cloning kit (Invitrogen, Carlsbad, CA) and then subcloned into the bait pAS vector (kind gift of Dr. Stephen J. Elledge, Baylor College of Medicine, Houston, TX). The entire PCR-amplified region was confirmed by sequencing. The prey pACT vector containing a cDNA encoding the $\mu 2$ chain of AP-2 (Ohno et al., 1996) was provided by Dr. Juan S. Bonifacino (National Institutes of Health, Bethesda, MD).

The HF7c strain was transformed sequentially with the pAS vector containing the L1 cytoplasmic domain (L1CD) sequences and with the pACT vector containing the $\mu 2$ chain sequence or no insert as a control. Yeast transformation was performed as described in the Clontech Yeast Two Hybrid Kit (Clontech Laboratories, Cambridge, UK).

Interactions between the three L1CD fusion proteins [baits in pAS2 (TRP1)] and the $\mu 2$ chain fusion protein [pACT (LEU2)] were tested by the ability of cotransformed yeast cells to express $\beta$-galactosidase and to grow on histidine-deficient plates. Cotransformed yeast colonies were grown on yeast dropout medium lacking leucine and tryptophan (C-LeuTrp), and then the cultures were tested for $\beta$-galactosidase activity by liquid assay as described (Golemis et al., 1996). To test for HIS3 expression, we streaked cells onto C-Leu-Trp-His plates in the presence of 5 or $10 \mathrm{~mm}$ 3-amino-triazole (3-AT). Growth was scored on the basis of the ability to form colonies within $10 \mathrm{~d}$ (Ohno et al., 1996).

Ultraviolet $(U V)$-induced cross-linking reaction. The photoreactive peptide (designated as *YQRL), which bears a portion of the cytosolic sequence of TGN38, including its YQRL tyrosine-based motif, was synthesized as previously described (Rapoport et al., 1997). The *YQRL peptide contains a UV-activatable cross-linker benzoylphenylalanine (BPA) at position Y-3 and is biotinylated at the $\mathrm{N}$ terminus (biotinKVTRRPK-BPA-SDYQRL). The YRSL peptide (FGEYRSLESD NEE) that corresponds to amino acids $1173-1185$ of the L1CD, the ARSL peptide (FGEARSLESDNEE) that has a Y1176A substitution, and the YSDN peptide (FGEYSDNEE) that lacks the RSLE sequence were synthesized by Research Genetics (Huntsville, AL).

The photoactivation cross-linking reaction was performed as described previously (Rapoport et al., 1997). Briefly, AP-2 complexes purified from calf brains were suspended in AP buffer [containing (in mM) 100 NaMES, $150 \mathrm{NaCl}, 1 \mathrm{EDTA}$, and 0.5 DTT, pH 7.0, plus $0.02 \% \mathrm{NaN}_{3}$ and $0.1 \%$ Triton X-100]. Then, $16 \mu$ l of this solution (final AP-2 concentration of $\sim 0.1 \mathrm{mg} / \mathrm{ml}$ ) was mixed with $2 \mu \mathrm{l}$ of the *YQRL peptide (final concentration of $0.2 \mu \mathrm{M}$ ) and $2 \mu \mathrm{l}$ of the competitor peptides (YRSL, ARSL, or YSDN peptide; final concentrations in the range of $0-1000$ $\mu \mathrm{M})$. The mixture was maintained on ice for $20 \mathrm{~min}$ in total darkness. The cross-linking reaction was triggered by a 3 min exposure to UV radiation. After the cross-linking reaction, $5 \mu$ l of $5 \times$ Laemmli sample buffer containing $\beta$-mercaptoethanol was added, and the samples were boiled for $3 \mathrm{~min}$. The cross-linked product was resolved by SDS-PAGE, followed by transfer to a nitrocellulose membrane and incubation with streptavidin-conjugated horseradish peroxidase (HRP; Boehringer Mannheim, Indianapolis, IN). The labeled bands were detected by enhanced chemiluminescence (Amersham, Arlington Heights, IL).

Immunoprecipitation and Western blot analysis. Brains from P7 Sprague Dawley rat pups were homogenized in (in mM) 20 Tris, pH 7.4, 1 EGTA, 1 sodium orthovanadate, and $10 p$-nitrophenyl phosphate (TEV-PNP) containing $0.32 \mathrm{M}$ sucrose, $200 \mathrm{~mm}$ Pefabloc SC, $1 \mu \mathrm{g} / \mathrm{ml}$ leupeptin, and $100 \mu \mathrm{g} / \mathrm{ml}$ aprotinin. The homogenates were separated by ultracentrifugation on a sucrose gradient for $45 \mathrm{~min}$ at $58,400 \times g$ at $4^{\circ} \mathrm{C}$. The plasma membrane layer was washed in TEV-PNP and then centrifuged for 30 min at $150,000 \times g$ at $4^{\circ} \mathrm{C}$ to pellet the membranes. The plasma mem- brane pellet was solubilized in TEV-PNP containing 1\% Triton X-100 and centrifuged for $45 \mathrm{~min}$ at $150,000 \times g$ at $4^{\circ} \mathrm{C}$ to remove insoluble material. Then the solubilized membrane fraction was incubated for $>4$ $\mathrm{hr}$ at $4^{\circ} \mathrm{C}$ with Sepharose beads conjugated to monoclonal anti-L1 antibody 74-5H7 (Lemmon et al., 1989), or to monoclonal anti-NCAM antibody 3F4 (kind gift of Dr. Urs Rutishauser, Case Western Reserve University, Cleveland, $\mathrm{OH}$ ). The beads were washed six times with TEV-PNP containing 1\% Triton X-100. Immunoprecipitates were mixed with sample buffer and boiled for $5 \mathrm{~min}$. Then the samples were separated by SDS-PAGE. The proteins were transferred to Immobilon-P polyvinylidene difluoride membrane (Millipore, Marlborough, MA), and the membrane then was blocked with $5 \%$ evaporated nonfat milk in Tris-buffered saline (TBS). The following commercial primary antibodies were used as recommended by the manufacturer: monoclonal antibodies against AP180, $\beta 1$ - and $\beta 2$-adaptin, and $\alpha$-adaptin (Sigma, St. Louis, MO). The monoclonal anti-NCAM antibody (3F4) was used at 10 $\mu \mathrm{g} / \mathrm{ml}$. The membrane was incubated with primary antibodies for $1 \mathrm{hr}$ at room temperature with shaking and was washed with $0.1 \%$ Tween- 20 in TBS. Then the membrane was probed with HRP-conjugated goat antimouse IgG (1:1000 in 5\% milk and $0.05 \%$ Tween-20/PBS, Boehringer Mannheim) for $1 \mathrm{hr}$, washed, and visualized by enhanced chemiluminescence (DuPont NEN, Boston, MA).

Cell culture. National Institutes of Health-3T3 (NIH-3T3) cells (American Type Culture Collection, Rockville, MD) were grown in DMEM (Life Technologies, Gaithersburg, MD) supplemented with $10 \%$ fetal bovine serum (FBS)

Dorsal root ganglia (DRGs) were dissected from embryonic day 10 chicks and dissociated sequentially with $2.4 \mathrm{U} / \mathrm{ml}$ dispase II (Boehringer Mannheim) and $0.1 \mathrm{mg} / \mathrm{ml}$ DNase (Boehringer Mannheim) in $\mathrm{Ca}^{2+}$ $\mathrm{Mg}^{2+}$-free PBS. The dissociated cells were resuspended in RPMI medium 1640 (Life Technologies) supplemented with L-glutamine, Na pyruvate, and $10 \%$ FBS and were preplated for $1 \mathrm{hr}$. Then $50 \mathrm{ng} / \mathrm{ml}$ nerve growth factor was added to the medium, and the neuron-enriched culture was prepared by replating the detached cells on glass coverslips sequentially coated with poly-L-lysine (Sigma), $10 \mu \mathrm{g} / \mathrm{ml}$ goat anti-human IgG (Fc-specific) (Sigma), and L1-Fc chimera. This chimeric molecule, which consists of the $\mathrm{Fc}$ region of human $\mathrm{IgG}$ and the whole extracellular domain of human L1, was constructed with the pIg-tail expression system (Novagen, Madison, WI), as described (Fransen et al., 1998).

The cultures were maintained in a humid atmosphere of $95 \%$ air $/ 5 \%$ $\mathrm{CO}_{2}$ at $37^{\circ} \mathrm{C}$.

DNA transfection. A pcDNA3-based expression plasmid containing a cDNA insert that codes for L1FL, L1Y1176A, or L1 $\triangle$ RSLE (see Fig. 1) was constructed as described (Kamiguchi and Lemmon, 1998). Expression constructs containing a cDNA insert that codes either for hemagglutinin (HA)-tagged wild-type or for HA-tagged K44A dynamin were provided by Dr. Sandra L. Schmid (The Scripps Research Institute, La Jolla, CA) (Damke et al., 1994).

NIH-3T3 cells were transfected with the L1 expression plasmids, using particle-mediated gene transfer (Helios Gene Gun System, Bio-Rad, Richmond, CA). According to the manufacturer's protocol, $50 \mathrm{mg}$ of gold particles $(1.0 \mu \mathrm{m}$ in diameter) was coated with $100 \mu \mathrm{g}$ of plasmid DNA. Then the DNA-coated particles in an ethanol suspension were loaded into Gold-Coat tubing and allowed to dry. NIH-3T3 cells were dissociated by trypsinization and resuspended in Leibovitz's L-15 medium (Life Technologies). Ten microliters of the cell suspension $\left(1 \times 10^{6}\right.$ cells $)$ were inoculated in the center of a $35 \mathrm{~mm}$ dish immediately before the gene delivery. For each transfection, $0.5 \mathrm{mg}$ of gold particles with $1 \mu \mathrm{g}$ of plasmid DNA was accelerated by 150 psi helium pressure to penetrate and transfect the target cells. The transfected cells were suspended in DMEM containing 10\% FBS and plated on a two-chamber plastic slide (Lab-Tek, Naperville, IL) sequentially coated with poly-L-lysine and 5 $\mu \mathrm{g} / \mathrm{cm}^{2}$ of fibronectin (Boehringer Mannheim).

Transfection of NIH-3T3 cells with the HA-tagged dynamin constructs was performed by $N-[1-(2,3-\mathrm{d}$ i o le o y loxy $)$ p r o pyl] $-N, N, N$ trimethylammonium methylsulfate (DOTAP) lipofection, according to the manufacturer's protocol (Boehringer Mannheim).

Generation of stably transfected NIH-3T3 cells. NIH-3T3 cells were transfected with pcDNA3 containing L1FL cDNA, using Lipofectamine reagent according to the manufacturer's protocol (Life Technologies). The cells were cultured in the presence of $600 \mu \mathrm{g} / \mathrm{ml}$ of G418 (Life Technologies) for 10-14 d. G418-resistant clones were characterized for L1FL expression by immunocytochemistry, and L1FL-expressing cells were selected by fluorescence-activated cell sorting (FACS) as described 
previously (Wong et al., 1995). The cells were grown further in $10 \%$ FBS-DMEM containing $600 \mu \mathrm{g} / \mathrm{ml}$ of G418.

Immunocytochemistry of NIH-3T3 cells. L1-transfected NIH-3T3 cells were processed for immunocytochemistry $24 \mathrm{hr}$ after gene transfer. In the experiment designed to label cell surface and endocytosed L1 differentially, living cells were incubated with rabbit polyclonal anti-human L1 antibody (1:250) (Wong et al., 1995) or Fab of the same antibody (25 $\mu \mathrm{g} / \mathrm{ml}$ ) for $1 \mathrm{hr}$ at $37^{\circ} \mathrm{C}$ to allow for L1 endocytosis. Then the cells were washed with DMEM at $4^{\circ} \mathrm{C}$ and were incubated with Texas Red (TxR)conjugated anti-rabbit IgG (1:200; Molecular Probes, Eugene, OR) for 30 min at $4^{\circ} \mathrm{C}$ to visualize cell surface $\mathrm{L} 1$. Then unlabeled anti-rabbit $\mathrm{IgG}$ (1:20; Molecular Probes) was used to block any remaining sites on the cell surface for $1 \mathrm{hr}$ at $4^{\circ} \mathrm{C}$. The cells were fixed with $4 \%$ paraformaldehyde for $30 \mathrm{~min}$, followed by blocking and permeabilization with $10 \%$ horse serum (HS) and $0.02 \%$ Triton X-100 in PBS. After washes, the cells were incubated with Oregon green (OrG)-conjugated anti-rabbit IgG (1:200; Molecular Probes) for $1 \mathrm{hr}$ at $20^{\circ} \mathrm{C}$ to label endocytosed L1antibody complexes.

In the experiment designed to double-label endocytosed L1 and transferrin receptors (TfR), endocytosed L1 was visualized as described above, and TfR was labeled with mouse monoclonal anti-TfR antibody (clone H68.4; Zymed Laboratories, San Francisco, CA). Living cells were incubated with Fab of rabbit anti-L1 antibody $(25 \mu \mathrm{g} / \mathrm{ml})$ for $1 \mathrm{hr}$ at $37^{\circ} \mathrm{C}$, washed at $4^{\circ} \mathrm{C}$, and incubated with unlabeled anti-rabbit IgG $(1: 20)$ for $1 \mathrm{hr}$ at $4^{\circ} \mathrm{C}$. After fixation, blocking, and permeabilization, the cells were incubated with anti-TfR antibody $(1: 100)$ for $16 \mathrm{hr}$ at $4^{\circ} \mathrm{C}$. Then the cells were incubated with OrG-conjugated anti-rabbit IgG (1:200) to visualize endocytosed $\mathrm{L} 1$ and with TxR-conjugated anti-mouse $\mathrm{IgG}$ (1:200) to visualize TfR.

In the experiment designed to visualize endocytosed L1 and transferrin (Tf), living cells were incubated with serum-free DMEM for $30 \mathrm{~min}$, followed by incubation with rabbit anti-L1 antibody (1:250) and TxRconjugated Tf (100 $\mu \mathrm{g} / \mathrm{ml}$; Molecular Probes) for $1 \mathrm{hr}$ at $37^{\circ} \mathrm{C}$ to allow for the endocytosis of both probes. The cells were incubated with unlabeled anti-rabbit $\mathrm{IgG}$, followed by fixation, blocking, and permeabilization. Endocytosed L1 was visualized with OrG-conjugated anti-rabbit IgG.

In the experiment to study the effects of wild-type and K44A dynamin on L1 endocytosis, L1FL-expressing NIH-3T3 cells (stable transfectant, selected by FACS) were transfected with HA-tagged dynamin constructs and processed for immunocytochemistry after $48 \mathrm{hr}$. Endocytosed L1 was labeled with rabbit anti-L1 antibody as described above, and then the cells were incubated with unlabeled anti-rabbit $\mathrm{IgG}$, followed by fixation, blocking, and permeabilization. HA-tagged dynamin was labeled by incubating the cells with mouse monoclonal anti-HA antibody (clone 12CA5, $10 \mu \mathrm{g} / \mathrm{ml}$; Boehringer Mannheim) for $16 \mathrm{hr}$ at $4^{\circ} \mathrm{C}$. After being washed, the cells were incubated with a mixture of TxR-X-conjugated anti-rabbit IgG (1:100; Molecular Probes) and OrG-conjugated antimouse IgG (1:200; Molecular Probes). The labeled cells were mounted with SlowFade (Molecular Probes).

Immunocytochemistry of DRG neurons. In the experiment designed to double-label L1 (74-5H7) and epidermal growth factor receptor pathway substrate clone 15 (Eps15), DRG cultures were fixed sequentially with (1) a cyclohexylamine/PIPES fixative containing $1 \%$ paraformaldehyde for 5 min (Luther and Bloch, 1989), followed by (2) a modified Bouin's solution containing saturated picric acid $(75 \mathrm{ml})$, formalin $(5 \mathrm{ml})$, glacial acetic acid $(5 \mathrm{ml})$, and distilled water $(20 \mathrm{ml})$ for $5 \mathrm{~min}$. After extensive washes, the cells were permeabilized and blocked with 10\% HS and $0.02 \%$ Triton-X 100 in PBS for $1 \mathrm{hr}$ and incubated with primary antibodies overnight at $4{ }^{\circ} \mathrm{C}$. The primary antibodies used were mouse monoclonal anti-L1CD antibody (74-5H7; 1:500) (Lemmon et al., 1989) and rabbit polyclonal anti-Eps15 antibody (1:500) (Cupers et al., 1997). After being rinsed, the cells were incubated for $1 \mathrm{hr}$ at room temperature with a mixture of OrG-conjugated anti-rabbit IgG (1:200) and TxR-Xconjugated anti-mouse IgG (1:100; Molecular Probes).

In the experiment designed to visualize endocytosed L1 in growth cones, living DRG neurons were incubated with rabbit polyclonal antichick L1 antibody (8D9; 1:250) (Lemmon and McLoon, 1986) for $15 \mathrm{~min}$ at $37^{\circ} \mathrm{C}$ to allow for $\mathrm{L} 1$ endocytosis. After being rinsed at $4^{\circ} \mathrm{C}$, the cells were fixed with $4 \%$ formaldehyde for $30 \mathrm{~min}$, washed, and incubated with unlabeled anti-rabbit IgG $(1: 20)$ to block the cell surface primary antibody. Then the cells were fixed again with $4 \%$ formaldehyde for $10 \mathrm{~min}$ to immobilize the unlabeled secondary antibody. After being washed, the cells were permeabilized and blocked with $10 \%$ HS and $0.02 \%$ Triton-X 100 in PBS for $1 \mathrm{hr}$ and incubated with mouse monoclonal anti-chick NCAM antibody (kind gift of Dr. Urs Rutishauser) for $16 \mathrm{hr}$ at $4^{\circ} \mathrm{C}$.

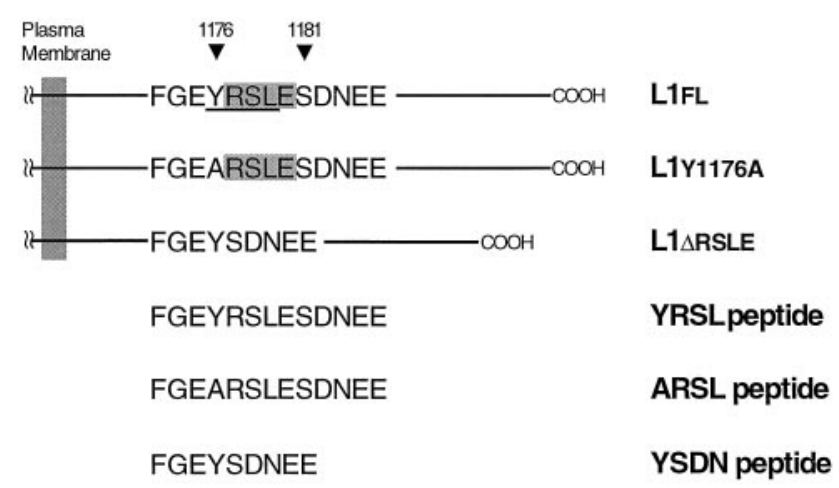

Figure 1. A portion of the L1 cytoplasmic domain is shown in the single-letter amino acid code. In the wild-type full-length L1 (L1FL), the cytoplasmic domain consists of 114 amino acids (1144-1257) and contains the RSLE sequence (shaded region), which is adjacent to Tyr ${ }^{1176}$. The resulting sequence of YRSL conforms to a tyrosine-based sorting motif, YxxL (underlined region). L1Y1176A has a single amino acid substitution $(Y 1176 A)$ that mutates a critical tyrosine residue in the motif. In the non-neuronal form of L1 (L1 $\triangle R S L E)$ that lacks the RSLE sequence, a hydrophobic amino acid leucine at position $\mathrm{Y}+3$ is replaced by a polar amino acid asparagine. Therefore, the tyrosine-based motif YRSL is disrupted in L1Y1176A and L1 1 RSLE. A cDNA that codes for the whole cytoplasmic domain of these forms of L1 (L1FLCD, L1 L1Y1176ACD) was used in the yeast two-hybrid system. The synthetic peptides (YRSL, ARSL, and YSDN), which correspond to a part of L1FLCD, L1 $\triangle \mathrm{RSLECD}$, or L1Y1176ACD, respectively, were used as a competitor in the UV-induced cross-linking experiments.

Endocytosed L1 was visualized with TxR-X-conjugated anti-rabbit IgG $(1: 100)$, and NCAM was visualized with OrG-conjugated anti-mouse IgG (1:200). The labeled cells were treated with SlowFade and mounted in Elvanol.

Confocal microscopy. Images of NIH-3T3 cells and growth cones of DRG neurons were taken with a Zeiss LSM 410 confocal laser microscope (Zeiss, Göttingen, Germany), using an argon/krypton laser (excitation lines, 488 and $568 \mathrm{~nm}$ ) and a $100 \times$ Plan-Neofluar, numerical aperture 1.3 , oil objective.

L1 and Eps15 distribution in growth cone images was analyzed by the colocalization function in the LSM 410 software (Zeiss). The program generates a scatterplot that compares pixel distribution and intensity in stored red and green images. Red pixels of increasing intensity $(0-255)$ distribute along the abscissa; green pixels distribute along the ordinate. Pixels with identical intensity values in the green and red channels are found along the $45^{\circ}$ diagonal and indicate colocalization of the fluorescently tagged antibodies that are used to detect different antigens. By selecting pixels near the $45^{\circ}$ diagonal, we can generate a mask that allows for the direct comparison of the colocalization of two antigens with the unprocessed image. Only high intensity pixels falling near the diagonal were selected to generate the mask showing colocalized distribution of L1 and Eps15. Images were processed minimally; montages were assembled in Adobe Photoshop and printed on a Tektronix Phaser 450 dye sublimation printer.

\section{RESULTS}

\section{The $\mu 2$ chain of AP-2 specifically recognizes and interacts with the tyrosine-based motif YRSL in the L1CD}

To test whether the tyrosine-based sorting motif YRSL in the L1CD interacts with the $\mu 2$ chain of AP-2, we used the yeast two-hybrid assay, using the whole L1CD as the bait fused to the Gal4 binding domain and the $\mu 2$ chain as the prey fused to the Gal4 activation domain. The cytoplasmic domains of wild-type and mutant forms of L1 (L1FLCD, L1 $\triangle$ RSLECD, and L1Y1176CD) used in the yeast two-hybrid assay are shown in Figure 1. Interactions between the three forms of L1CD and the $\mu 2$ chain were tested by the ability of cotransformed yeast cells to grow on 


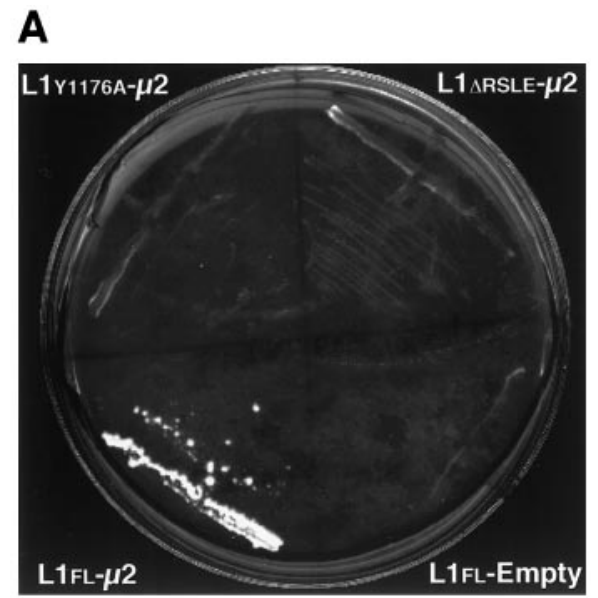

B

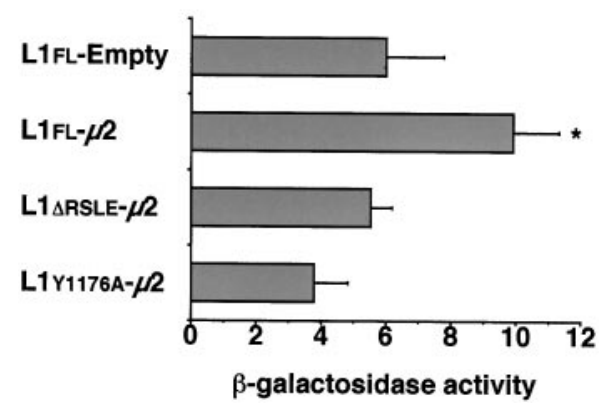

Figure 2. The yeast two-hybrid assay demonstrates the interaction between the YRSL sequence of the L1CD and the $\mu 2$ chain of AP-2. $A$, Yeast cells, which were cotransformed with L1FLCD and $\mu 2$ sequences $(L 1 F L-\mu 2)$, were able to grow and form colonies on histidine-deficient plates in the presence of $5 \mathrm{~mm} 3$-AT between 3 and $5 \mathrm{~d}$ after plating. However, cotransformants containing either L1 $\triangle \mathrm{RSLECD}$ or L1Y1176ACD and $\mu 2$ sequences (L1DRSLE- $\mu 2$ or $L 1 Y 1176 A-\mu 2$, respectively) did not form colonies after $10 \mathrm{~d}$ under the same conditions. $B, L 1 F L-\mu 2$ expressed a significantly higher level of $\beta$-galactosidase activity than a background level (L1FL-Empty). However, both L1 $\triangle R S L E-\mu 2$ and L1Y1176A- $\mu 2$ expressed comparable levels of $\beta$-galactosidase activity to the background level. Values represent the mean $\pm \mathrm{SD}$ of five determinations. ${ }^{*} p<$ 0.0005; one-way ANOVA, followed by post hoc Fisher's PLSD as compared with L1FL-Empty.

histidine-deficient plates or to express $\beta$-galactosidase activity. On C-Leu-Trp plates, which select for the presence of the bait and prey vectors, all double transformants were able to grow and produce colonies between 1 and $3 \mathrm{~d}$ after plating. However, on histidine-deficient plates (C-Leu-Trp-His) in the presence of 3-AT (5 or $10 \mathrm{~mm}$ ), only double transformants expressing L1FLCD and $\mu 2$ grew and produced colonies between 3 and $5 \mathrm{~d}$ (Fig. 2A). All of the other transformants did not form colonies after $10 \mathrm{~d}$ under the same conditions. Similar results were obtained with 5 and $10 \mathrm{~mm} 3$-AT. The $\beta$-galactosidase liquid assay showed that yeast cells cotransformed with pAS containing the L1FLCD sequence and pACT containing the $\mu 2$ chain sequence expressed a significantly higher level of $\beta$-galactosidase activity than the control strain, which carried pAS with the L1FLCD sequence and empty pACT (Fig. 2B). However, the $\beta$-galactosidase activity of yeast cells that were cotransformed with pAS containing either the L1Y1176ACD or L1 1 RSLECD sequence and pACT containing the $\mu 2$ chain sequence was comparable to the control level. These results demonstrate that the
L1FLCD, but not L1Y1176ACD or L1 $\mathrm{RSLECD}$, interacts with the isolated $\mu 2$ chain of AP-2.

In previous studies it has been demonstrated that a photoreactive peptide (*YQRL) bearing a portion of the cytosolic sequence of TGN38, including its tyrosine-based sorting motif, specifically labels the $\mu 2$ subunit of the intact AP- 2 complex (Rapoport et al., 1997). To test whether the synthetic peptide, including the YRSL sequence in the L1CD, also interacts with the $\mu 2$ chain, we set up an experiment in which a biotinylated $*$ YQRL peptide was incubated with purified AP-2 in the presence of increasing concentrations of the L1CD peptides (YRSL, ARSL, and YSDN peptides; see Fig. 1). After photoactivation, samples were analyzed by SDS-PAGE and probed with HRP-streptavidin to reveal the product composed of $\mu 2$ cross-linked to ${ }^{*}$ YQRL (Fig. 3). The YRSL peptide interfered with the cross-linking reaction between the *YQRL peptide and the $\mu 2$ chain. This competitive interaction of the YRSL peptide is dependent on its tyrosine residue, because the ARSL peptide did not interfere with the crosslinking reaction. Further confirmation of the specificity of the interaction was obtained by showing that another peptide, YSDN, also failed to interfere with the cross-linking reaction. On the basis of these observations, we conclude that the interaction between the YRSL peptide and the AP-2 complex in solution is specific and that this interaction occurs through a contact that involves the $\mu 2$ chain of the AP- 2 complex.

\section{The AP-2 complex associates with L1 in rat brain}

In vitro biochemical assays have shown that the YRSL sequence in the L1CD specifically binds the $\mu 2$ chain of AP-2. To examine whether L1 associates with AP-2 in vivo, we probed L1 immunoprecipitates from rat brain membrane extracts with antibodies against two of the subunits of AP-2 and against AP180. Anti- $\beta 1$ and $\beta 2$-adaptin antibody labeled a band of $\sim 105 \mathrm{kDa}$ (Fig. 4 , lane 2). Anti- $\alpha$-adaptin antibody, which is known to react with 105 and $110 \mathrm{kDa}$ forms of $\alpha$-adaptin in brain preparations (Ahle and Ungewickell, 1990), labeled two bands of the corresponding sizes in L1 immunoprecipitates (Fig. 4, lane 3). These data indicate that the AP-2 complex associates with L1 in rat brain. AP180, which is a clathrin assembly protein in coated vesicles (Ahle and Ungewickell, 1986), coimmunoprecipitated with L1 (Fig. 4, lane 1), further confirming that L1 forms a complex with clathrinassociated proteins in brain. As a negative control, antibodies to NCAM readily detected NCAM in the brain membrane extracts (Fig. 4, lane 5), but not in the L1 immunoprecipitate (Fig. 4, lane 4 ). Another negative control is provided in Figure 4 (lanes 7-10), which shows that neither AP-2 nor AP-180 coimmunoprecipitated with NCAM from rat brain membrane extracts.

\section{L1 is endocytosed via a clathrin-mediated pathway}

The interaction of the AP-2 adaptor with the tyrosine-based signal of the L1CD suggests that L1 is endocytosed via an AP-2 and clathrin-mediated pathway. Therefore, we examined whether or not L1 is internalized from the cell surface, using L1FLtransfected NIH-3T3 cells. Since it is difficult to visualize L1 clearly in intracellular vesicular compartments by conventional immunocytochemistry because of a much higher level of L1 expression on the cell surface, we used two secondary antibodies with different conjugates to label cell surface L1 and endocytosed L1 differentially. Intracellular L1 in vesicular compartments, possibly endosomes, are shown clearly in L1FL-transfected NIH-3T3 cells (Fig. 5A,B). Labeling of these structures is specific for L1, because the cytoplasm of untransfected NIH-3T3 cells was never 

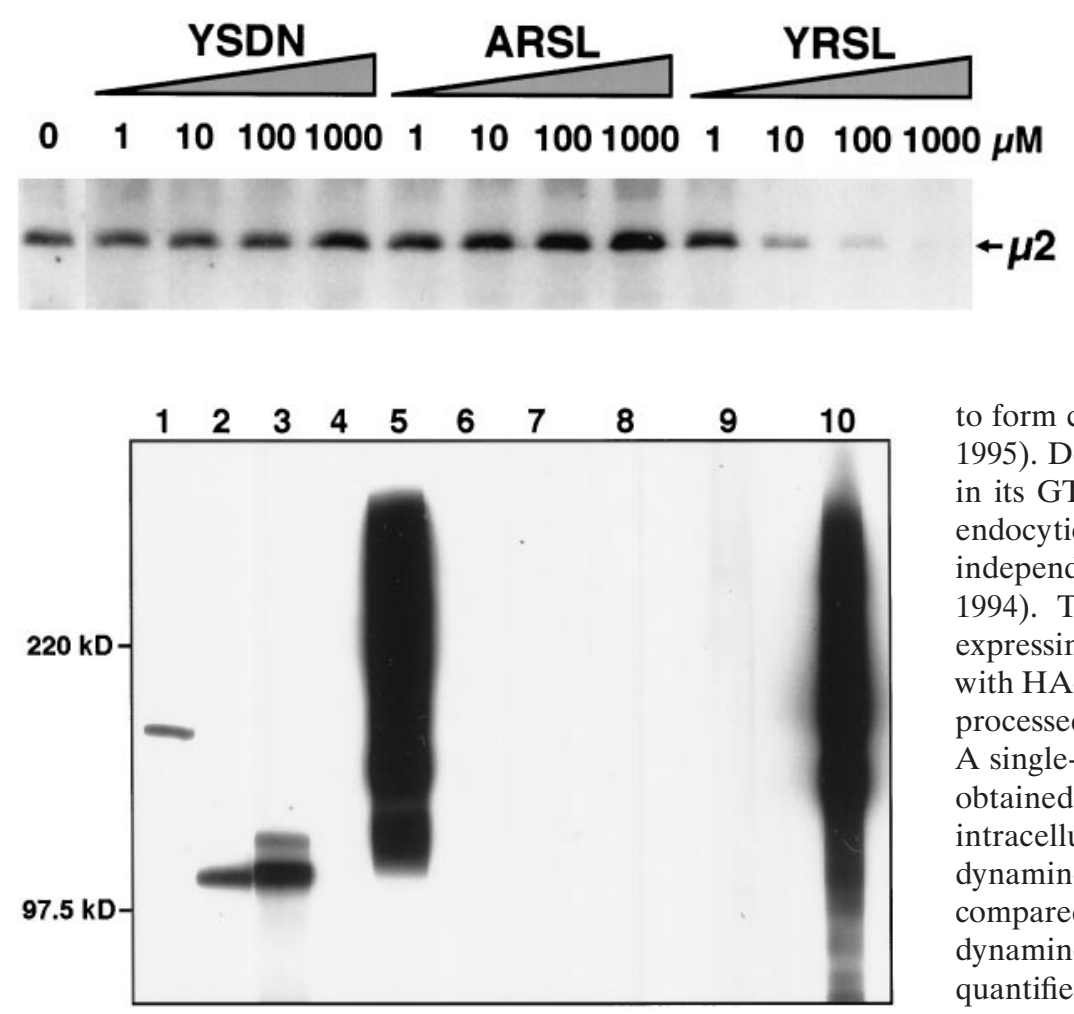

Figure 4. L1 immunoprecipitates from rat brain membrane extracts were probed with anti-AP180 antibody (lane 1 ), anti- $\beta 1$ - and $\beta 2$-adaptin antibody (lane 2 ) or anti- $\alpha$-adaptin antibody (lane 3 ), and no primary antibody control (lane 6), showing that AP-2 and AP180 coimmunoprecipitated with L1. As a control, the L1 immunoprecipitates (lane 4) and rat brain membrane extracts (lane 5) were probed with anti-rat NCAM antibody. As another control, NCAM immunoprecipitates from rat brain membrane extracts were probed with anti-AP180 antibody (lane 7), anti- $\beta 1$ and $\beta 2$-adaptin antibody (lane 8 ), anti- $\alpha$-adaptin antibody (lane 9), or anti-NCAM antibody (lane 10).

labeled under this immunocytochemical protocol (data not shown). Furthermore, because the cells were incubated with anti-L1 antibody only when they were alive, all of the positive staining inside the cell represents endocytosed L1. This observation demonstrates that L1 is internalized from the cell surface. A bivalent antibody against L1 tended to label a greater number of intracellular structures than Fab, suggesting that cross-linking L1 on the cell surface triggers endocytosis of L1. As shown in Figure $5 B$, we often observed L1 in endocytic compartments enriched in one side of the cell near the lateral membrane.

Subsequently, we conducted experiments to study whether or not L1 endocytosis occurs via a clathrin-dependent pathway. Transferrin (Tf) is known to be internalized via a clathrinmediated mechanism after binding to a transferrin receptor TfR (Klausner et al., 1983; Trowbridge et al., 1993), which carries a tyrosine-based endocytic signal that interacts with AP-2 (Ohno et al., 1995). We found that, in L1FL-transfected NIH-3T3 cells, all of the endocytosed L1FL labeled by anti-L1 antibody was found in vesicular compartments (most likely endosomes) that contained TxR-Tf (Fig. 5C-E), indicating that L1 endocytosis occurs via the same pathway as that of Tf. To confirm further that L1 endocytosis is clathrin-dependent, we tested whether disruption of dynamin function blocks L1 endocytosis. Dynamin, a member of the GTPase superfamily, self-assembles into rings at the neck of clathrin-coated pits and plays a critical role in the fission reaction
Figure 3. The $\mu 2$ chain of AP- 2 was labeled by the *YQRL peptide containing photoreactive cross-linker in the absence or presence of the competitor peptides (YRSL, ARSL, or $Y S D N$; see Fig. 1). The concentrations of each competitor peptide are indicated in the figure. The YRSL peptide that carries the tyrosine-based motif interfered with the crosslinking reaction between the ${ }^{*}$ YQRL peptide and the $\mu 2$ chain when the YRSL peptide was presented at a concentration as low as $10 \mu \mathrm{M}$. Both the ARSL and YSDN peptides lacking the motif failed to interfere with the cross-linking reaction at concentrations up to $1 \mathrm{~mm}$. to form coated vesicles (Hinshaw and Schmid, 1995; Takei et al., 1995). Dominant-negative dynamin, which has a K44A mutation in its GTP-binding domain, specifically blocks the formation of endocytic coated vesicles but does not perturb clathrinindependent endocytosis (van der Bliek et al., 1993; Damke et al., 1994). Therefore, we set up an experiment in which L1FLexpressing NIH-3T3 cells were selected by FACS and transfected with HA-tagged wild-type or K44A dynamin. Then the cells were processed for immunocytochemistry to visualize endocytosed L1. A single-section confocal slice of a dynamin-transfected cell was obtained such that the section contained the maximal number of intracellular L1-positive compartments in that cell. K44A dynamin-transfected cells showed impaired L1 endocytosis as compared with untransfected (Fig. 5F,G) and wild-type dynamin-transfected cells (Fig. 5H,I). L1 endocytosis was semiquantified by counting the number of intracellular L1-positive compartments per cell: $3.7 \pm 3.6$ in K44A dynamin-expressing cells $(n=33)$ and $26.3 \pm 20.6$ in wild-type dynamin-expressing cells $(n=32)$ (mean $\pm \mathrm{SD} ; p<0.0001$; unpaired Student's $t$ test). We also confirmed that K44A dynamin blocks Tf endocytosis but does not affect dextran uptake, a marker for clathrin-independent pinocytosis (data not shown). These results provide solid evidence that L1 is endocytosed via clathrin-coated vesicles.

To examine the role for the YRSL sequence in L1 endocytosis, we transfected NIH-3T3 cells with an L1FL, L1Y1176A, or L1 1 RSLE construct. These forms of L1 have been shown to be integrated properly into the plasma membrane in NIH-3T3 cells (Kamiguchi and Lemmon, 1998). All of the endocytosed L1FL, which was labeled by anti-L1 Fab, was found in vesicular compartments containing TfR (Fig. 6A-C). Although both L1Y1176A and L1 $\triangle$ RSLE were internalized from the cell surface, these forms of L1 did not colocalize with TfR in their endocytic pathways (Fig. $6 D-I)$. The failure of the L1 mutants to colocalize with the TfR supports the idea that the YRSL sequence is critical for determining the pathways by which L1 is endocytosed.

\section{L1 is endocytosed at the rear of axonal growth cones}

Homophilic binding between substrate-bound L1 and axonal L1 stimulates axon growth in vitro (Lemmon et al., 1989). In the axonal growth cone, L1-mediated adhesive interactions may be dynamically regulated to create a front-versus-rear asymmetry in growth cone-substrate adhesion (Kamiguchi and Lemmon, 1997). This is believed to be necessary for growth cone migration (Lauffenburger and Horwitz, 1996). One possible mechanism to create a gradient of adhesivity is that L1 is internalized from the growth cone surface in a spatially regulated manner. To confirm this possibility, we examined colocalization of L1 and Eps15, a protein present in coated pits of the clathrin-mediated endocytic pathway (Tebar et al., 1996; van Delft et al., 1997), in DRG growth cones growing on an L1 substrate. We used a monoclonal antibody, 74-5H7 (Lemmon et al., 1989), that binds to a phosphorylation-sensitive site in the L1CD and does not label cell 

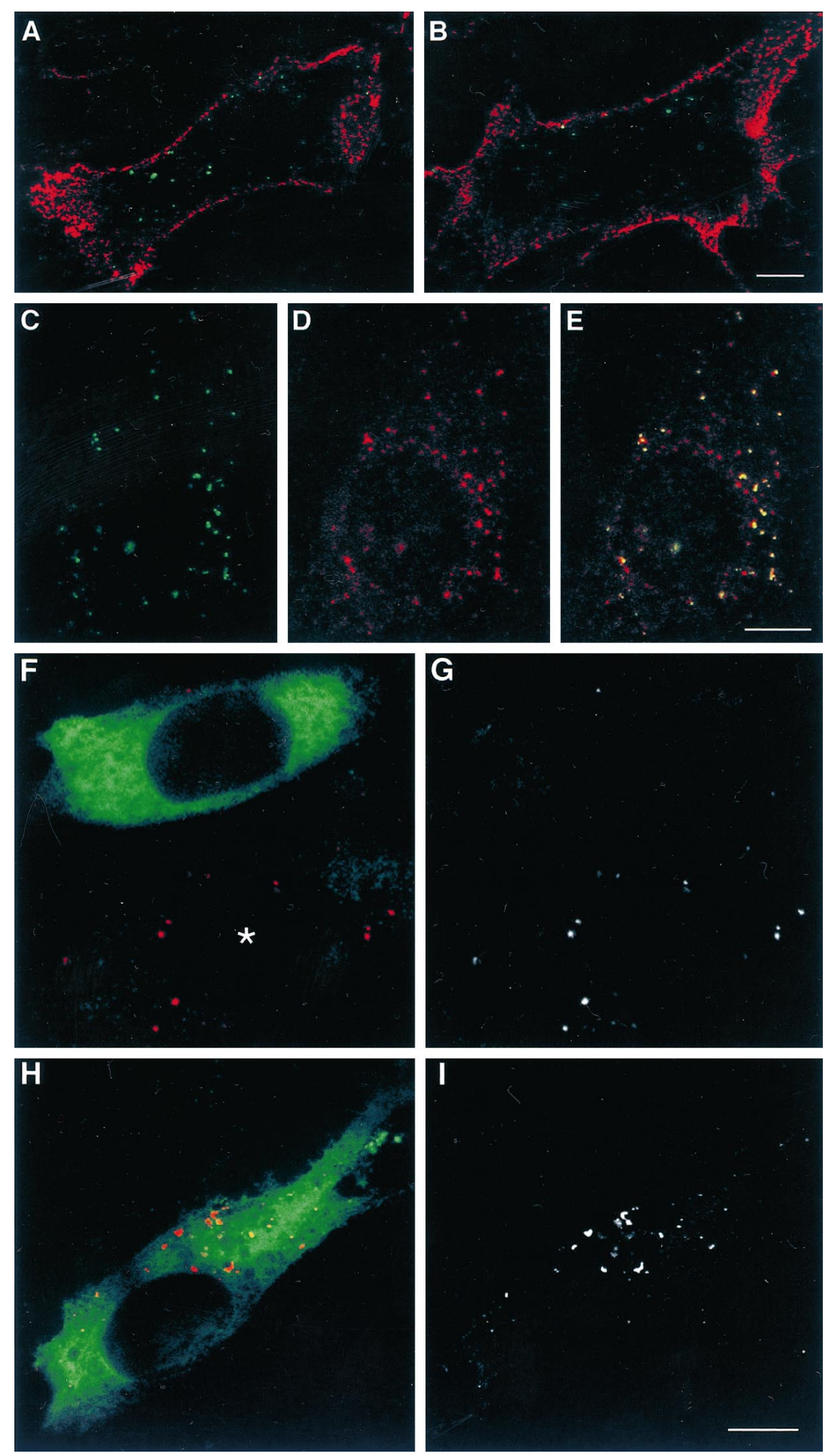

Figure 5. $A, B$, Shown are confocal sections ( $0.83 \mu \mathrm{m}$ in thickness) of L1FL-transfected NIH-3T3 cells in which cell surface L1 and endocytosed L1 were differentially labeled. Living cells were incubated with bivalent anti-L1 antibody $(A)$ or anti-L1 Fab $(B)$ for 1 hr to allow for L1 endocytosis. A superimposed image in which cell surface $\mathrm{L} 1$ is colored in red and endocytosed $\mathrm{L} 1$ in green is shown. Scale bar, $10 \mu \mathrm{m}$. $C-E$, Confocal sections $(0.83 \mu \mathrm{m}$ in thickness) of a L1FL-transfected NIH-3T3 cell that was incubated with anti-L1 antibody and TxR-conjugated Tf for $1 \mathrm{hr}$ to allow for the endocytosis of both probes. Shown are endocytosed L1 $(C)$, endocytosed $\mathrm{Tf}(D)$, and a superimposed image showing colocalization of L1 and Tf as evidenced by yellow $(E)$. Scale bar, $10 \mu \mathrm{m} . F-I$, Confocal sections ( $0.71 \mu \mathrm{m}$ in thickness) of L1FL-expressing NIH-3T3 cells that were transfected with K44A dynamin $(F, G)$ or wild-type dynamin $(H, I)$. Endocytosed $\mathrm{L} 1$ is colored in red and transfected dynamin in green $(F, H)$. To facilitate the visualization of endocytosed L1, we have shown the red channel only in black and white $(G, I)$. An asterisk indicates a cell that was not transfected with K44A dynamin. Scale bar, $10 \mu \mathrm{m}$. 

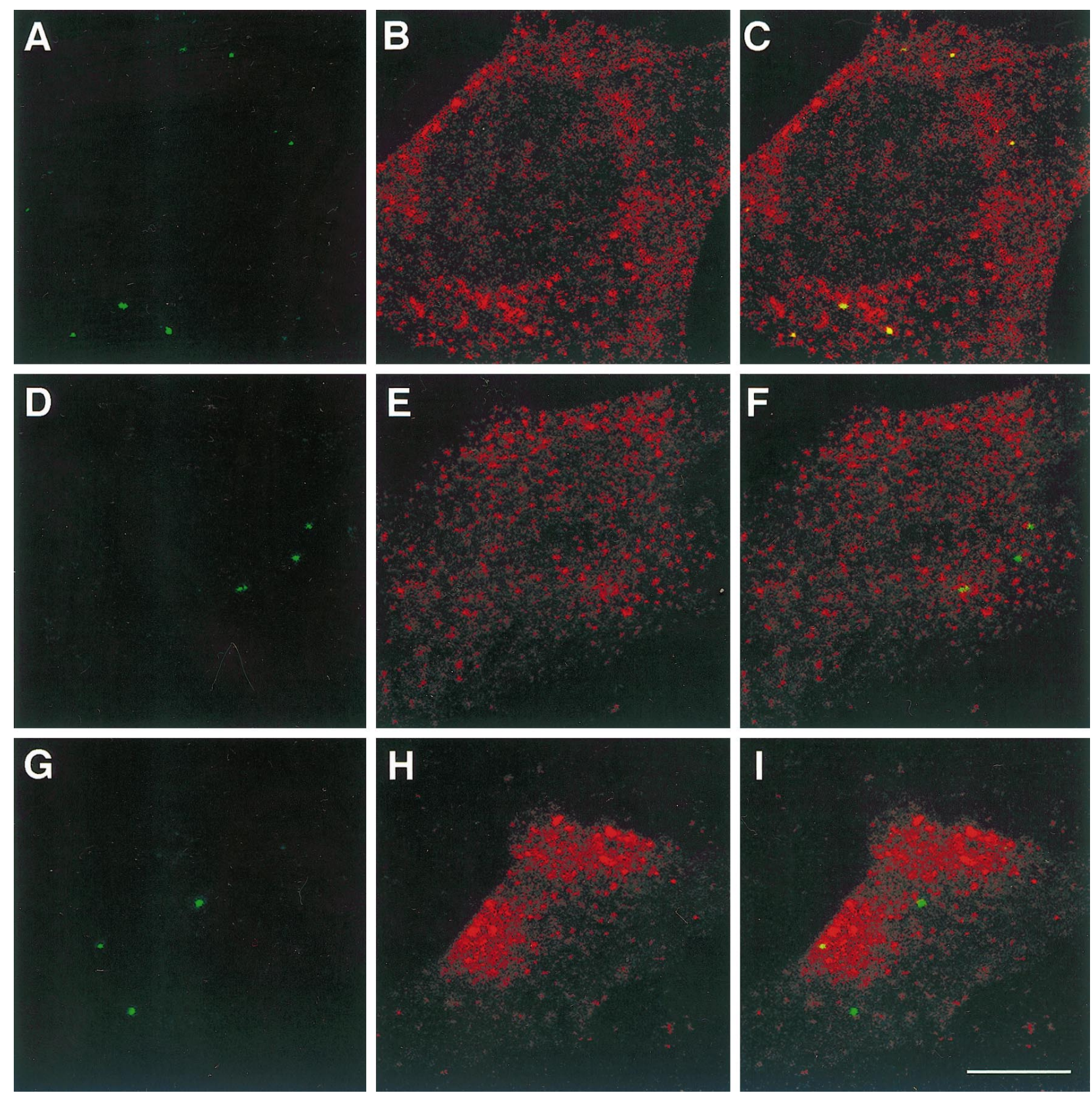

Figure 6. Confocal sections $(0.83 \mu \mathrm{m}$ in thickness) of NIH-3T3 cells expressing L1FL $(A-C)$, L1Y1176A $(D-F)$, or L1 $\Delta$ RSLE $(G-I)$. Living cells were incubated with anti-L1 Fab for $1 \mathrm{hr}$ to label endocytosed L1, and the cells were double-labeled with anti-TfR antibody. Endocytosed L1 ( $A, D, G)$, TfR $(B, E, H)$, and superimposed images $(C, F, I)$ are shown. Yellow indicates colocalization of endocytosed L1 and TfR. Scale bar, $10 \mu \mathrm{m}$.

surface L1 except at cell-cell contact sites (A. W. Schaefer, S. Storms, G. Landreth, and V. Lemmon, unpublished observations). This antibody labeled vesicular structures in the growth cone (Fig. 7A). The growth cone was double-labeled with antiEps15 antibody (Fig. 7B), showing the concentrated expression of Eps15 at the rear of the growth cone where L1 and Eps15 had colocalized (Fig. 7C). This colocalization pattern was confirmed further by using the colocalization function in the LSM 410 software (Fig. 7D). The site-specific colocalization of L1 and Eps15 suggests that clathrin-mediated endocytosis of L1 preferentially occurs at the rear of growth cones. To confirm this idea further, we visualized intracellular L1 that had been endocytosed during 15 min in DRG growth cones growing on an L1 substrate
(Fig. $7 E, F)$. In the majority of growth cones examined, endocytosed L1 is restricted to the rear and the central domain of the growth cone and is absent from the peripheral domain.

\section{DISCUSSION}

Examples of cells rapidly altering CAM function are found in diverse systems, from leukocyte rolling and extravasation through the vascular endothelium to synaptic plasticity in the nervous system (Ebnet et al., 1996; Fields and Itoh, 1996; Rutishauser and Landmesser, 1996; Weber et al., 1996). A common strategy for controlling CAM function is to regulate the adhesivity of the extracellular domain by changing the conformation of its cytoplasmic tail. This inside-out signaling has been well documented 

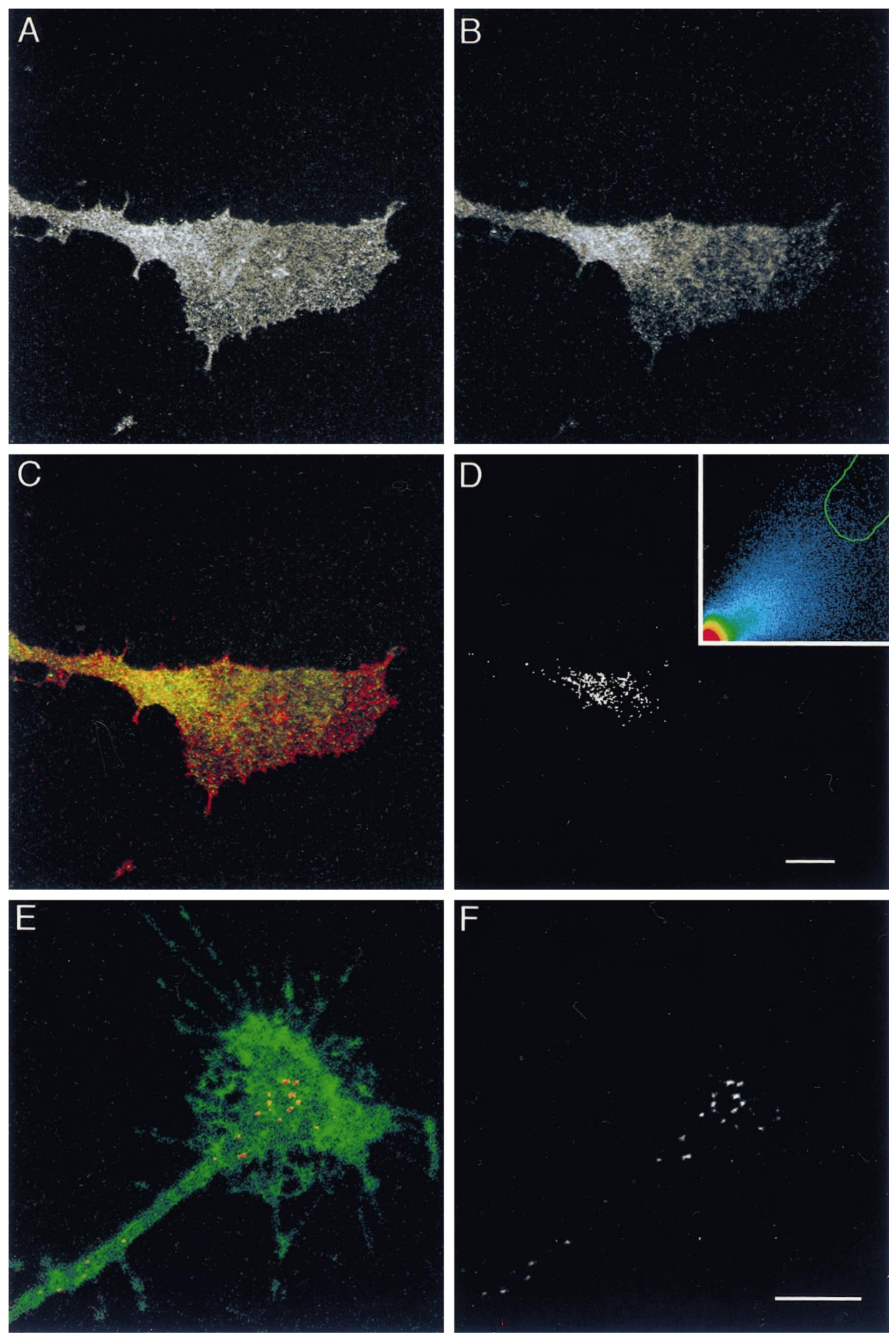

Figure 7. $A-D$, Confocal sections $(0.71 \mu \mathrm{m}$ in thickness $)$ of a DRG growth cone growing on an $\mathrm{L} 1$ substrate. The growth cone was double-labeled with anti-L1CD antibody $(74-5 \mathrm{H} 7)(A)$ and anti-Eps15 antibody $(B)$. Superimposition of the images with L1 colored in red and Eps15 in green exhibits colocalization (yellow) at the rear of the growth cone $(C)$. A black and white mask shows the colocalized distribution of L1 and Eps15 (D). High intensity pixels falling within the green tracing on the scatterplot (inset) were chosen to generate the mask (see Materials and Methods for details). Scale bar, 10 $\mu \mathrm{m}$. $E, F$, Confocal sections $(0.83 \mu \mathrm{m}$ in thickness) of a DRG growth cone growing on an L1 substrate. The living neuron was incubated with anti-L1 antibody for $15 \mathrm{~min}$ to label endocytosed L1. The cell was double-labeled with anti-NCAM antibody to visualize the outline of the growth cone. Endocytosed L1 is colored in red and NCAM in green $(E)$. To facilitate visualization of endocytosed L1, we have shown the red channel only in black and white $(F)$. Scale bar, $10 \mu \mathrm{m}$.

for integrins and cadherins (Aberle et al., 1996; Kolanus and Seed, 1997). However, it is known that removing the cytoplasmic domain of L1 and its Drosophila homolog, neuroglian, does not alter their adhesivity (Hortsch et al., 1995; Wong et al., 1995).
This suggests that alterations, such as phosphorylation or conformational changes, in the L1CD may not regulate the adhesivity of its extracellular domain directly. Therefore, another strategy may be used to alter L1-mediated adhesion. For example, the amount 
of L1 expression on the cell surface could be controlled by regulating its internalization from the plasma membrane.

The interaction between cytoplasmic coat proteins and specific signals in the cytoplasmic tails of integral membrane proteins is considered a general mechanism for controlling protein sorting in the endocytic pathways. The tyrosine-based motif, Yxx $\varnothing$, is the best characterized of the endocytic sorting signals that are recognized by and interact with the clathrin-associated AP-2 complex (Ohno et al., 1995, 1996; Boll et al., 1996; Rapoport et al., 1997). We have demonstrated that the tyrosine-based sorting motif, YRSL, in the L1CD specifically interacts with the $\mu 2$ chain of AP-2 in vitro and that L1 associates with both AP-2 and AP180 in vivo. Because the interaction of tyrosine-based sorting signals with AP-2 governs endocytosis of the signal-bearing proteins (Kirchhausen et al., 1997; Marks et al., 1997), the binding of L1 with AP-2 strongly suggests that L1 is endocytosed via an AP-2 and clathrin-mediated pathway. This also has been demonstrated in the present study by showing that L1 endocytosis is blocked by dominant-negative dynamin, which is known specifically to block clathrin-dependent endocytosis (van der Bliek et al., 1993; Damke et al., 1994).

The YRSL sequence is conserved not only in mammalian L1 but also in chick and zebrafish homologs of L1 (Hlavin and Lemmon, 1991; Tongiorgi et al., 1995; Buchstaller et al., 1996). It also is conserved in other members of the L1 subfamily, including neurofascin and NrCAM (Kayyem et al., 1992; Volkmer et al., 1992), implying that the YRSL is a common signal mediating endocytosis of L1 family CAMs. The L1CD contains three other tyrosine residues (Hlavin and Lemmon, 1991), although none of them constitutes a recognized sorting sequence that conforms to either the $\mathrm{Yxx} \emptyset$ motif or another type of tyrosine-based motif, NPXY (Chen et al., 1990; Kirchhausen et al., 1997; Marks et al., 1997). The YRSL sequence in the L1CD is followed immediately by a cluster of acidic amino acids containing Ser ${ }^{1181}$ that can be phosphorylated by casein kinase II (CKII; see Fig. 1) (Wong et al., 1996). This consensus motif for CKII phosphorylation also is conserved in neurofascin and NrCAM. Several proteins localized to the trans-Golgi network (TGN), such as furin and varicellazoster virus glycoprotein I, carry an acidic stretch with CKII phosphorylation sites, which is situated C-terminal to tyrosinebased sorting signals. Internalization of these proteins from the cell surface is dependent on both the CKII phosphorylation sites and the tyrosine-based signals (Voorhees et al., 1995; Alconada et al., 1996), implying that the phosphorylation of L1 by CKII also might play a role in L1 endocytosis.

The present study has shown that endocytosed L1FL colocalizes with Tf and TfR in L1FL-transfected NIH-3T3 cells. The endocytic and recycling pathways of $\mathrm{Tf}$ and $\mathrm{TfR}$ are well characterized (Dautry-Varsat, 1986). The TfR bears a tyrosine-based signal YTRF in its cytoplasmic tail, which is recognized by the $\mu 2$ chain of AP-2 (Ohno et al., 1995). The Tf/TfR complex formed at the cell surface is endocytosed through the clathrin-coated pits by interacting with AP-2. Upon the uncoating of the endocytic vesicles and dissociation of AP-2, the Tf/TfR complex is recycled to the cell surface via early and recycling endosomes, but it does not enter lysosomally directed pathways (Dautry-Varsat et al., 1983; Dautry-Varsat, 1986). It is also possible that, after clathrinmediated endocytosis, L1FL is targeted to early and recycling endosomes to be directed back to the cell surface, considering the significant colocalization of endocytosed L1FL and Tf/TfR. The failure of endocytosed L1Y1176A and L1 $\triangle$ RSLE to colocalize with $\mathrm{Tf} / \mathrm{TfR}$ suggests that these forms of L1 are internalized via a different pathway from Tf/TfR uptake, for example, via clathrinindependent endocytic pathways. These pathways, which include caveolae and macropinocytosis, are known to exist in many types of mammalian cells (Mellman, 1996). The observations that endocytosed L1FL, but not L1Y1176A and L1 1 RSLE, colocalized with Tf/TfR indicate that the YRSL sequence affects the endocytic traffic pathways of L1, most likely by interacting with AP-2.

Endocytosis and recycling mechanisms are important not only for ligand-transporting receptors, such as TfRs, but also for CAMs, such as integrins, which are involved in cell motility. Cell migration is a complex process requiring coordinated functions of cytoskeletal, membrane, and adhesion systems. In migrating cells and in the growth cone of extending axons, the backward flow of the actin cytoskeleton is viewed as a force-generating system. When coupled to an extracellular substrate via CAMs, the retrograde actin flow can generate force that is required for the anterograde cell movement (Lin et al., 1994; Mitchison and Cramer, 1996). CAMs, which have been translocated to the rear by coupling to the backward actin flow, are internalized from the cell surface and recycled to the leading edge (Lawson and Maxfield, 1995; Lauffenburger and Horwitz, 1996). The internalization of CAMs provides a mechanism for creating a gradient of adhesive strength from the front to the rear of migrating cells or axonal growth cones, which is thought to be required for cell locomotion (Lauffenburger and Horwitz, 1996).

The present work has demonstrated that L1, as visualized by 74-5 H7, colocalizes with Eps15 only at the rear of axonal growth cones. Because Eps15 is present in an early phase of endocytosis (clathrin-coated pits) (Tebar et al., 1996), the site-specific colocalization of L1 and Eps15 strongly suggests that L1 is endocytosed preferentially at the rear of growth cones. This was confirmed further by directly visualizing endocytosed L1 in the growth cones. Because endocytosed L1 is restricted to the subregion of growth cones where L1 and Eps15 colocalize, it is most likely that the clathrin-mediated mechanism is the major endocytic route for $\mathrm{L} 1 \mathrm{in}$ neurons. The observation that $74-5 \mathrm{H} 7$ labeled L1 in vesicular compartments also at the peripheral domain of growth cones implies that L1 has been transported anterogradely after endocytosis. The preferential endocytosis of L1 at the rear of growth cones and the subsequent anterograde transport are consistent with the general concept of CAM trafficking in migrating cells. Further studies are needed to clarify what mechanism is involved in regulating the L1 and AP-2 interaction to allow the site-specific endocytosis of L1. It has been speculated that $\mathrm{Tyr}^{1176}$ in the L1CD, which is a critical residue of the tyrosine-based sorting signal YRSL, may be subject to phosphorylation (Heiland et al., 1996). Considering that the critical tyrosine has to be in a nonphosphorylated state for the signals to be active in sorting (Boll et al., 1996; Ohno et al., 1996), the phosphorylation of $\mathrm{Tyr}^{1176}$ may be involved in regulating L1 endocytosis.

Another important implication of CAM endocytosis is that a cell could regulate the surface expression of CAMs in response to its extracellular environment. For example, integrin expression on the neuronal cell surface is dynamically regulated by the extracellular ligand density, providing a mechanism by which neurons can maintain proper adhesive interactions over a broad range of ligand concentrations (Condic and Letourneau, 1997). It is also likely that extracellular ligand binding to L1 influences L1 endocytosis. Because cis-interactions of L1 with other Ig superfamily members are thought to initiate intracellular signaling in response to ligand binding (Kamiguchi and Lemmon, 1997), it 
would be interesting to study whether the cis-interactions could regulate $\mathrm{L} 1$ endocytosis.

In adult brain, L1 subfamily members are found in the hippocampus and cerebellum (Brümmendorf and Rathjen, 1994), regions in which the remodeling of synaptic connections is a critical and ongoing process. Indeed, L1 has been implicated in hippocampal long-term potentiation (Lüthl et al., 1994) and in spatial learning (Fransen et al., 1998). Endocytosis of apCAM, a member of the Ig superfamily of CAMs, is important during synaptic remodeling after conditioning in the gill withdrawal reflex in Aplysia (Bailey et al., 1992; Mayford et al., 1992). It is plausible that endocytosis of L1 also might play a role in synaptic remodeling.

\section{REFERENCES}

Aberle H, Schwartz H, Kemler R (1996) Cadherin-catenin complex: protein interactions and their implications for cadherin function. J Cell Biochem 61:514-523.

Ahle S, Ungewickell E (1986) Purification and properties of a new clathrin assembly protein. EMBO J 5:3143-3149.

Ahle S, Ungewickell E (1990) Auxilin, a newly identified clathrinassociated protein in coated vesicles from bovine brain. J Cell Biol 111:19-29.

Alconada A, Bauer U, Hoflack B (1996) A tyrosine-based motif and a casein kinase II phosphorylation site regulate the intracellular trafficking of the varicella-zoster virus glycoprotein I, a protein localized in the trans-Golgi network. EMBO J 15:6096-6110.

Bailey CH, Chen M, Keller F, Kandel ER (1992) Serotonin-mediated endocytosis of apCAM: an early step of learning-related synaptic growth in Aplysia. Science 256:645-649.

Boll W, Ohno H, Songyang Z, Rapoport I, Cantley LC, Bonifacino JS, Kirchhausen T (1996) Sequence requirements for the recognition of tyrosine-based endocytic signals by clathrin AP-2 complexes. EMBO J 15:5789-5795.

Brümmendorf T, Rathjen FG (1994) Cell adhesion molecules. 1. Immunoglobulin superfamily. Protein Profile 1:951-1058.

Buchstaller A, Kunz S, Berger P, Kunz B, Ziegler U, Rader C, Sonderegger P (1996) Cell adhesion molecules NgCAM and axonin-1 form heterodimers in the neuronal membrane and cooperate in neurite outgrowth promotion. J Cell Biol 135:1593-1607.

Chen W-J, Goldstein JL, Brown MS (1990) NPXY, a sequence often found in cytoplasmic tails, is required for coated pit-mediated internalization of the low density lipoprotein receptor. J Biol Chem 265:3116-3123.

Cohen NR, Taylor JSH, Scott LB, Guillery RW, Soriano P, Furley AJW (1997) Errors in corticospinal axon guidance in mice lacking the neural cell adhesion molecule L1. Curr Biol 8:26-33.

Condic ML, Letourneau PC (1997) Ligand-induced changes in integrin expression regulate neuronal adhesion and neurite outgrowth. Nature 389:852-856.

Cupers P, ter Haar E, Boll W, Kirchhausen T (1997) Parallel dimers and anti-parallel tetramers formed by epidermal growth factor receptor pathway substrate clone 15 (Eps15). J Biol Chem 272:33430-33434.

Dahme M, Bartsch U, Martini R, Anliker B, Schachner M, Mantei N (1997) Disruption of the mouse L1 gene leads to malformations of the nervous system. Nat Genet 17:346-349.

Damke H, Baba T, Warnock DE, Schmid SL (1994) Induction of mutant dynamin specifically blocks endocytic coated vesicle formation. J Cell Biol 127:915-934.

Dautry-Varsat A (1986) Receptor-mediated endocytosis: the intracellular journey of transferrin and its receptor. Biochimie 68:375-381.

Dautry-Varsat A, Ciechanover A, Lodish HF (1983) pH and the recycling of transferrin during receptor-mediated endocytosis. Proc Natl Acad Sci USA 80:2258-2262.

Ebnet K, Kaldjian EP, Anderson AO, Shaw S (1996) Orchestrated information transfer underlying leukocyte endothelial interactions. Annu Rev Immunol 14:155-177.

Fields RD, Itoh K (1996) Neural cell adhesion molecules in activitydependent development and synaptic plasticity. Trends Neurosci 19:473-480.

Fransen E, D’Hooge R, Van Camp G, Verhoye M, Sijbers J, Reyniers E,
Soriano P, Kamiguchi H, Willemsen R, Koekkoek SKE, De Zeeuw CI, De Deyn PP, Van der Linden A, Lemmon V, Kooy RF, Willems PJ (1998) L1 knock-out mice show dilated ventricles, vermis hypoplasia, and impaired exploration patterns. Hum Mol Genet 7:999-1009.

Gallusser A, Kirchhausen T (1993) The $\beta 1$ and $\beta 2$ subunits of the AP complexes are the clathrin coat assembly components. EMBO J 12:5237-5244.

Golemis EA, Gyuris J, Brent R (1996) Interaction trap/two-hybrid system to identify interacting proteins. In: Current protocols in molecular biology (Ausubel FM, Brent R, Kingston RE, Moore DD, Seidman JG, Smith JA, Struhl K, eds), pp 20.1.1-20.1.28. New York: Wiley.

Heiland PC, Hertlein B, Traub O, Griffith LS, Schmitz B (1996) The neural adhesion molecule L1 is phosphorylated on tyrosine and serine residues. NeuroReport 7:2675-2678.

Hinshaw JE, Schmid SL (1995) Dynamin self-assembles into rings suggesting a mechanism for coated vesicle budding. Nature 374:190-192.

Hlavin ML, Lemmon V (1991) Molecular structure and functional testing of human L1CAM: an interspecies comparison. Genomics 11:416-423.

Hortsch M (1996) The L1 family of neural cell adhesion molecules: old proteins performing new tricks. Neuron 17:587-593.

Hortsch M, Wang Y, Marikar Y, Bieber AJ (1995) The cytoplasmic domain of the Drosophila cell adhesion molecule neuroglian is not essential for its homophilic adhesive properties in S2 cells. J Biol Chem 270:18809-18817.

Kamiguchi H, Lemmon V (1997) Neural cell adhesion molecule L1: signaling pathways and growth cone motility. J Neurosci Res 49:1-8.

Kamiguchi H, Lemmon V (1998) A neuronal form of the cell adhesion molecule L1 contains a tyrosine-based signal required for sorting to the axonal growth cone. J Neurosci 18:3749-3756.

Kamiguchi H, Hlavin ML, Yamasaki M, Lemmon V (1998) Adhesion molecules and inherited diseases of the human nervous system. Annu Rev Neurosci 21:97-125.

Kayyem JF, Roman JM, de la Rosa EJ, Schwarz U, Dreyer WJ (1992) Bravo/Nr-CAM is closely related to the cell adhesion molecules L1 and $\mathrm{Ng}-\mathrm{CAM}$ and has a similar heterodimer structure. J Cell Biol 118:1259-1270.

Kirchhausen T, Bonifacino JS, Riezman H (1997) Linking cargo to vesicle formation: receptor tail interactions with coat proteins. Curr Opin Cell Biol 9:488-495.

Klausner RD, Van Renswoude J, Ashwell G, Kempf C, Schechter AN, Dean A, Bridges KR (1983) Receptor-mediated endocytosis of transferrin in K562 cells. J Biol Chem 258:4715-4724.

Kolanus W, Seed B (1997) Integrins and inside-out signal transduction: converging signals from PKC and PIP3. Curr Opin Cell Biol 9:725-731.

Lauffenburger DA, Horwitz AF (1996) Cell migration: a physically integrated molecular process. Cell 84:359-369.

Lawson MA, Maxfield FR (1995) $\mathrm{Ca}^{2+}$ - and calcineurin-dependent recycling of an integrin to the front of migrating neutrophils. Nature 377:75-79.

Lemmon V, McLoon S (1986) The appearance of an L1-like molecule in the chick primary visual pathway. J Neurosci 6:2987-2994.

Lemmon V, Farr K, Lagenaur C (1989) L1-mediated axon outgrowth occurs via a homophilic binding mechanism. Neuron 2:1597-1603.

Lin CH, Thompson CA, Forscher P (1994) Cytoskeletal reorganization underlying growth cone motility. Curr Opin Neurobiol 4:640-647.

Luther PW, Bloch RJ (1989) Formaldehyde-amine fixatives for immunocytochemistry of cultured Xenopus myocytes. J Histochem Cytochem 37:75-82.

Lüthl A, Laurent JP, Figurov A, Muller D, Schachner M (1994) Hippocampal long-term potentiation and neural cell adhesion molecule L1 and NCAM. Nature 372:777-779.

Marks MS, Ohno H, Kirchhausen T, Bonifacino JS (1997) Protein sorting by tyrosine-based signals: adapting to the Ys and wherefores. Trends Cell Biol 7:124-128.

Mayford M, Barzilai A, Keller F, Schacher S, Kandel ER (1992) Modulation of an NCAM-related adhesion molecule with long-term synaptic plasticity in Aplysia. Science 256:638-644.

Mellman I (1996) Endocytosis and molecular sorting. Annu Rev Cell Dev Biol 12:575-625.

Mitchison TJ, Cramer LP (1996) Actin-based cell motility and cell locomotion. Cell 84:371-379.

Miura M, Kobayashi M, Asou H, Uyemura K (1991) Molecular cloning of cDNA encoding the rat neural cell adhesion molecule L1-two L1 
isoforms in the cytoplasmic region are produced by differential splicing. FEBS Lett 289:91-95.

Nelson KK, Lemmon SK (1993) Suppressors of clathrin deficiency: overexpression of ubiquitin rescues lethal strains of clathrin-deficient Saccharomyces cerevisiae. Mol Cell Biol 13:521-532.

Ohno H, Stewart J, Fournier MC, Bosshart H, Rhee I, Miyatake S, Saito T, Gallusser A, Kirchhausen T, Bonifacino JS (1995) Interaction of tyrosine-based sorting signals with clathrin-associated proteins. Science 269:1872-1875.

Ohno H, Fournier MC, Poy G, Bonifacino JS (1996) Structural determinants of interaction of tyrosine-based sorting signals with the adaptor medium chains. J Biol Chem 271:29009-29015.

Palecek SP, Schmidt CE, Lauffenburger DA, Horwitz AF (1996) Integrin dynamics on the tail region of migrating fibroblasts. J Cell Sci 109:941-952.

Rapoport I, Miyazaki M, Boll W, Duckworth B, Cantley LC, Shoelson S, Kirchhausen T (1997) Regulatory interactions in the recognition of endocytic sorting signals by AP-2 complexes. EMBO J 16:2240-2250.

Rutishauser U, Landmesser L (1996) Polysialic acid in the vertebrate nervous system: a promoter of plasticity in cell-cell interactions. Trends Neurosci 19:422-427.

Takeda Y, Asou H, Murakami Y, Miura M, Kobayashi M, Uyemura K (1996) A nonneuronal isoform of cell adhesion molecule L1: tissuespecific expression and functional analysis. J Neurochem 66:2338-2349.

Takei K, McPherson PS, Schmid SL, De Camilli P (1995) Tubular membrane invaginations coated by dynamin rings are induced by GTP- $\gamma$ S in nerve terminals. Nature 374:186-190.

Tebar F, Sorkina T, Sorkin A, Ericsson M, Kirchhausen T (1996) Eps15 is a component of clathrin-coated pits and vesicles and is located at the rim of coated pits. J Biol Chem 271:28727-28730.

Tongiorgi E, Bernhardt RR, Schachner M (1995) Zebrafish neurons express two L1-related molecules during early axonogenesis. J Neurosci Res 42:547-561.

Trowbridge IS, Collawn JF, Hopkins CR (1993) Signal-dependent membrane protein trafficking in the endocytic pathway. Annu Rev Cell Biol 9:129-161.

van Delft S, Schumacher C, Hage W, Verkleij AJ, van Bergen en Henegouwen PMP (1997) Association and colocalization of Eps15 with adaptor protein-2 and clathrin. J Cell Biol 136:811-821.

van der Bliek AM, Redelmeier TE, Damke H, Tisdale EJ, Meyerowitz EM, Schmid SL (1993) Mutations in human dynamin block an intermediate stage in coated vesicle formation. J Cell Biol 122:553-563.

Volkmer H, Hassel B, Wolff JM, Frank R, Rathjen FG (1992) Structure of the axonal surface recognition molecule neurofascin and its relationship to a neural subgroup of the immunoglobulin superfamily. J Cell Biol 118:149-161.

Voorhees P, Deignan E, van Donselaar E, Humphrey J, Marks MS, Peters PJ, Bonifacino JS (1995) An acidic sequence within the cytoplasmic domain of furin functions as a determinant of trans-Golgi network localization and internalization from the cell surface. EMBO J 14:4961-4975.

Weber C, Alon R, Moser B, Springer TA (1996) Sequential regulation of $\alpha 4 \beta 1$ and $\alpha 5 \beta 1$ integrin avidity by CC chemokines in monocytes: implications for transendothelial chemotaxis. J Cell Biol 134: 1063-1073.

Wong EV, Cheng G, Payne HR, Lemmon V (1995) The cytoplasmic domain of the cell adhesion molecule L1 is not required for homophilic adhesion. Neurosci Lett 200:155-158.

Wong EV, Schaefer AW, Landreth G, Lemmon V (1996) Casein kinase II phosphorylates the neural cell adhesion molecule L1. J Neurochem 66:779-786. 